\title{
ENTREVISTA: HIPERTEXTO NO COTIDIANO ESCOLAR
}

Eduardo S. Junqueira

Esta entrevista foi realizada em setembro de 2012, nas dependências da Universidade Federal de Minas Gerais, por ocasião do seminário intitulado Novos Letramentos, Novas Agências, realizado pelo Grupo de Trabalho Linguagem e Tecnologias (LINTEC ${ }^{1}$ ), da Associação Nacional de Pesquisa em Letras e Linguística (ANPOLL), presidido pela professora Dra. Vera Lúcia Menezes de Oliveira e Paiva (UFMG) e pelo Prof. Dr. Júlio Cesar Araújo (UFC).

O entrevistador, professor Dr. Eduardo S. Junqueira é docente da Universidade Federal Virtual do Ceará e desenvolve pesquisas sobre novos letramentos, inclusão digital, práticas comunicativas de jovens, informática educativa e educação a distância. O entrevistado, professor Dr. Luiz Fernando Gomes, leciona na UFAL Universidade Federal de Alagoas e é professor-colaborador na Unicamp, com pesquisas sobre linguagem e tecnologia.

A entrevista é baseada nos livros de Gomes, Hipertextos Multimodais: leitura e escrita na era digital ${ }^{2}$ e Hipertexto no Cotidiano Escolar ${ }^{3}$, publicados recentemente, e aborda questões relativas à definição e tipologia do hipertexto; funções e tipos de links e suas implicações para a leitura e a escrita de hipertextos e de sistemas hipertextuais, tendo como horizonte as práticas letradas digitais e sua inserção no cotidiano escolar.

Eduardo Junqueira: Logo na introdução do seu livro, você diz que a comunicação mediada pela tecnologia provoca mudanças em nossa maneira de ler e descrever. Quais são as principais mudanças?

Luiz Fernando: Bom, as mudanças começam pelos diferentes suportes para leitura que hoje são disponibilizados, a partir do PC, do notebook, dos tablets, dos telefones celulares, dos ipads e assim por diante. Dessa forma, cada suporte, cada mídia vai proporcionar, possibilitar novas formas de interação do leitor com o texto. Acrescenta-se a isso o fato de que as mídias digitais permitem a veiculação de textos multimodais; desta forma temos então: textos verbais, orquestrados com imagens, imagens em movimento, com diferentes tipografias e cores tipográficas, temos também além do vídeo, o áudio e, por exemplo, no Youtube, temos vídeos e podemos interpretar o que está acontecendo neles também pelos gestos das pessoas. Portanto, aquilo que chamamos aqui de leitura passa a ser outra coisa que se mistura um pouco com a ideia de assistir, como assistir à televisão, assistir a um vídeo. Então assistir a um vídeo no Youtube, pode ser entendido, nesse caso, como leitura, e torna-se, portanto, objeto de estudo da linguística, que tradicionalmente reservava esse termo apenas ao texto verbal. Além da ampliação do conceito de leitura há também a redefinição, digamos assim, do que é livro. Na nossa cabeça ainda surge como algo que é encadernado, com capa, etc. Hoje, podemos ter livros do tipo do e-book, por exemplo, que é uma outra forma de

\footnotetext{
${ }^{1} \mathrm{http}$ ://anpoll.org.br/gt/linguagem-e-tecnologias/

2 http://loja.livrariadapaco.com.br/hipertextos.html

3 GOMES, L.F. Trabalhando com Hipertexto no Cotidiano Escolar. São Paulo: Cortez Editora, 2011. Disponível em: $\quad$ http://www.cortezeditora.com.br/DetalheProduto.aspx?ProdutoId=\%7B003C780661FA-E011-82D1-842B2B1656E4\%7D
} 
livro. Portanto, com relação à leitura, muda bastante, pois mudando o suporte e as linguagens, mudam-se os hábitos, os locais de leitura. O tempo da leitura também muda e muda o conceito do que chamamos de leitura, que muitas vezes ainda está enraizado na ideia de leitura de um texto exclusivamente verbal, como já comentamos aqui no caso da mediação tecnológica já há uma ampliação utilizando-se outras linguagens.

Para podermos ler esses textos que comentamos aqui, alguém precisa escrever, portanto, imaginemos que as mudanças não sejam somente na leitura, mas também na escritura. Ela passa a requerer do produtor do texto conhecimentos mínimos, por exemplo, de onde o texto vai ser lido ou disponibilizado, se há necessidade de fazer versões diferentes para determinados suportes - nós sabemos que essa é uma das questões fundamentais. Nós podemos saber como escrever para publicar em nosso blog, mas não sabemos, por exemplo, escrever para publicar no Youtube, porque lá é um site onde uma imagem, especialmente a imagem em movimento, é central, então escrever para aquele leitor e para aquela mídia é bem diferente do que escrever um texto exclusivamente verbal. Portanto, muda também a forma de pensarmos o que é a escrita. Por que, ao escrevermos, temos que já começar a pensar não apenas no leitor, não apenas no conteúdo, na mensagem, no que nos motiva a escrever, mas também na recepção mediada, quer dizer, em qual aparelho, sobre qual tecnologia o leitor vai ter acesso àquele nosso conteúdo proposto.

Fora isso, uma questão que nos interessa mais de perto é a linguagem. Nós podemos dominar em certa medida a linguagem verbal escrita e produzirmos textos bons, seja qual for o sentido desse termo bom. Mas escrever um texto ou projetar um texto onde tenhamos imagens fixas ou em movimento, onde possamos explorar os significados da tipografia selecionada, onde possamos repensar o áudio e muitas vezes os gestos conforme o tipo de texto exige do autor, do designer do texto, habilidade e conhecimentos que ainda não são tratados pela escola, como bem sabemos e mais do que isso, acabam sendo aprendidos fora da escola e, digamos, que até de uma maneira meio capenga, meio improvisada, até porque vamos aprendendo essas técnicas à medida que estamos precisando, quer dizer, não de um currículo pré-planejado, mas sim do atendimento de necessidades imediatas, que muitas vezes percebemos, mas não conhecemos de fato. Portanto, podemos acabar aprendendo o uso e a combinação dessas linguagens de uma forma talvez não tão bem acabada, posto que não é escolarizada, quanto aquela que seria se fosse escolarizada.

Eduardo Junqueira: Qual é a relação dessas mudanças com o trabalho do professor na escola?

Luiz Fernando: Vivo me questionando se todas as mudanças ou todas as possibilidades, ou mesmo ainda todo o potencial de mudança que as tecnologias trazem em relação aos usos das linguagens; se tudo isso tem que passar pelo professor e pela escola. Pode parecer contraditório, mas é difícil imaginar a formação de professores, mesmo que seja a formação contínua que dê conta da voracidade tecnológica, desenvolvimento de ferramentas, de softwares e possibilidades de comunicação e o professor e a escola dando conta de aprender, compreender, estudar e transformar todo esse conhecimento em algum tipo de prática pedagógica que possa depois ser levada à escola e passado para os alunos em diversas series e níveis escolares.

Por outro lado, não consigo imaginar qual seria então, a função, o papel da escola, na sociedade atual, se não for primordialmente ajudar os alunos a fazerem leituras do mundo e leituras críticas. Agora, essas leituras passam, como observamos, pelas linguagens. Então eu não diria que como você pergunta: como fica o trabalho do professor na escola, que mudanças trazem. A resposta eu não sei, porque há tantas 
coisas que precisariam ser mudadas, tantas novidades e há tantas potencialidades de uso da linguagem de acordo com diferentes tecnologias que selecionemos ou elejamos para levar para o cotidiano escolar, que é praticamente impossível, pelo menos para mim, nesse momento, imaginar qual seria o trabalho do professor, aliás mal consigo imaginar que professor seria esse.

Me pego pensando também, se eu seria um bom professor nessas circunstâncias, porque mesmo nós que somos estudiosos desses temas, também carecemos ainda, de experiências pedagógicas que nos ajudem a definir abordagens escolares para o ensino, trabalho, desenvolvimento, dessas linguagens, que chamamos de multimodais, no cotidiano escolar. Diria eu que, de fato, temos, fatalmente, mudanças no trabalho do professor, no modelo de escola, provavelmente no modelo de aula, no modelo de sala de aula, no tempo de aula, enfim, as mudanças não seriam, nessa minha perspectiva, apenas no professor. Acho até um pouco doloroso despejar no professor toda a responsabilidade por essas tantas mudanças que as tecnologias venham a acarretar. Por outro lado, o professor, sem o apoio institucional das escolas, também teria dificuldades, mesmo que bem preparado, devidamente consciente do seu novo papel, mesmo assim teria dificuldades caso a escola, os colegas e todos os outros envolvidos no contexto escolar não pensassem da mesma forma, não fossem alinhados a essa mesma nova proposta. Então, pensando dessa forma, ter um computador por aluno, ou um tablet por aluno como se divulgou recentemente, pode ser somente mais um equívoco na relação tecnologia-escola.

Eduardo Junqueira: O que é o hipertexto? Ele existe somente na tela do computador?

Luiz Fernando: Embora possa haver algumas divergências na definição de hipertexto, a definição em que eu tenho trabalhado e que dá conta das necessidades que eu tenho discutido e vivenciado, me diz que o hipertexto é um texto exclusivamente digital, cuja diferença fundamental, em relação ao texto, digamos tradicional, é a presença e a centralidade dos links, e se a gente imaginar então que a presença de links é fundamental e que os links só existem no ambiente digital, então o hipertexto só tem sua plenitude, enquanto texto digital. Como você pergunta se ele só existe na tela de um computador, podemos dizer que não, atualmente temos outros dispositivos que trabalham com texto eletrônico, que não podemos, a rigor, chamar de computador, então diria assim que ele só pode existir digitalmente, mas não necessariamente no que nós imaginamos que seja o computador.

Agora, o que nós temos muito são textos digitalizados que não são hipertextos, por exemplo, os arquivos em PDF, arquivos “.doc”, que são digitalizados, enfim a maior parte dos textos que circulam na internet, não são hipertextos. Nós temos sistemas hipertextuais, como por exemplo, os sites, portais de notícias, etc. Ao abrirmos um portal, temos vários links que nos levam a vários conteúdos, mas não necessariamente esses conteúdos são hipertextuais, somente o sistema é. Por exemplo, o site do Scielo ${ }^{4}$, nós temos condições de abrir um índice, os resumos e depois clicar no resumo de um texto, ele abre uma página e nós podemos ler ou imprimir e até fazer o download, mas esse texto não é hipertextual, somente o sistema onde ele está colocado é hipertextual e nós acessamos esse texto através de links organizacionais. Em um site institucional, como o de uma universidade, caso você queira acessar um edital, você usa de hipertextos.

No início, eu ingenuamente pensei, quando comecei a estudar os hipertextos,

\footnotetext{
${ }^{4}$ Scientific Electronic Library Online - SciELO é uma biblioteca eletrônica que abrange uma coleção selecionada de periódicos científicos brasileiros.
} 
que tudo na web era hipertextual e que nós deixaríamos de escrever, do modo como vínhamos fazendo tradicionalmente, para uma forma completamente diferente, e que haveria a disponibilidade de programas mais adequados à produção de hipertextos, mas nós temos o contrário, nós temos sistemas hipertextuais, como os blogs, sites, o próprio Google, mas nós não temos um programa propício para a produção hipertextual, ou seja, podemos acrescentar links num processador de textos, ou mesmo em uma apresentação, mas eles não são feitos para isso, o que você pode fazer é escrever alguma coisa e enviá-la para ser postada em algum site ou algum blog. O que se pode fazer é escrever curtos, médios ou grandes textos, e publicá-los em sistemas hipertextuais, mas nós continuamos a escrever textos. Não acredito mais que iremos deixar de escrever textos para escrever hipertextos.

O mais fácil é continuar a ensinar nas escolas a leitura e produção de textos, que possam, depois, ser disponibilizados em ambientes hipertextuais. O ponto negativo é que esses ambientes e sistemas, em sua maioria, têm um default de design, ou seja, o sistema acaba sendo uma espécie de coautor e, sendo assim, participa da produção textual. Imaginem, escrevermos em coautoria com sistemas hipertextuais!

Como editor da revista Quaestio, aqui da Universidade de Sorocaba, eu tenho lutado para que a revista seja disponibilizada online, para que os textos acadêmicos sejam publicados de forma hipertextual, por exemplo, se o usuário estiver lendo um resumo, as palavras-chave, autores, obras, etc. seriam links que, quando clicados, levariam para o segmento, ou âncora respectiva. Ou seja, a leitura de textos acadêmicos poderia ter outros percursos, a partir já do resumo. Hoje, porém, nós continuamos escrevendo textos como se fossem ser publicados em uma revista impressa, mas são disponibilizados em formato digital, para serem, de fato, impressos ou lidos na tela sem links. É um pouco esquizofrênico isso, eu acho.

Há alguns sites em que os autores exploram todas as potencialidades hipertextuais, porém são sites autorais, difíceis, complexos e de autores especialistas, não são sites que nós normalmente faríamos. O hipertexto em sua potencialidade criadora, libertadora, como inclusive preconizou o Pierre Lévy, ainda não se concretizou plenamente, de forma generalizada, porque não conseguimos fazer hipertextos autorais, pois o máximo que conseguimos fazer é "linkar" os nossos textos em sistemas hipertextuais que no todo acaba configurando como se fosse um hipertexto, mas de fato não é.

Eduardo Junqueira: O link ou âncora é o elemento central do hipertexto?

Luiz Fernando: Sim, como a gente acabou de comentar, sem link e âncora o hipertexto não existe. Interessante é que somente os textos que nós "linkamos" e acessamos em um momento de leitura é que compõem o hipertexto. Por exemplo, se eu acessar um site que tenha cinco mil textos e eu já vou ler três ou quatro links, obviamente que os outros textos eu não li, mas eles fazem parte de um sistema hipertextual, só que os hipertextos que eu conheço são somente os dos quatro textos que li.

A centralidade do link tem uma dupla face: a do link e a do leitor. Para o link ser central é necessário que o leitor o identifique como tal e que decida por clicar ou não. Dessa forma, o link pode não atuar como tal, a menos que o leitor o ative. Em termos de texto, o link é central, mas, em termos de leitura, o leitor é o elemento central porque é a partir dele que o hipertexto se configura como hipertexto, se ele não clicar em nenhum link, só terá lido um texto!

Eduardo Junqueira: Qual a diferença entre links semânticos e links estruturais? 
Luiz Fernando: Essa é uma questão relativamente fácil de comentar, mas dificílima, segundo a minha experiência, de se trabalhar com esses conceitos na escola. Veja só. Os links estruturais são os links que estruturam a navegação de um site ou um portal. Imaginando um portal de uma universidade, você tem seções que são estruturadas através de links, então esses links são as portas para você entrar, por exemplo, na biblioteca, secretaria, concursos e editais, notícias, etc. Os links estruturais têm a finalidade de estruturar o sistema hipertextual.

Mas esses links também têm uma propriedade semântica: se você clica em biblioteca você deverá ser redirecionado para uma biblioteca virtual, portanto todo link estrutural também é em parte semântico, e esse já é um problema porque se um aluno entrar no site da universidade e quiser acessar uma revista acadêmica publicada pela a instituição, ele poderá encontrar termos como: publicações, revistas, periódicos, etc. Porém, um link estrutural com o nome de "periódicos" pode não remeter diretamente à ideia de periódicos acadêmicos, que é, digamos, uma expressão de uso mais restrito que revista, por exemplo. Essa é uma questão interessante: como trabalhar semanticamente os links estruturais, pois seus significados são culturais, além de contextuais, e podem ser lidos diferentemente por diferentes leitores. Há um esforço dos designers para "padronizar" os termos, a fim de diminuir barreiras interpretativas.

Vou dar outro exemplo: seria como se nós pensássemos que os carros, embora eles possam mudar de modelo ou de ano eles são, na essência, iguais, o volante é no lado esquerdo, você tem o freio, embreagem, acelerador e etc. Do mesmo modo, há uma tendência de padronização dos sistemas hipertextuais para que a navegação seja mais fluida, mais naturalizada.

Os links semânticos exercem também uma função retórica. A retórica, como sabemos, é a arte do convencimento e os links semânticos são oportunidades ou possibilidades criadas pelo autor do texto ou do sistema hipertextual que sugerem, de forma mais ou menos convincente diferentes caminhos de leitura. A grande jogada é que esses links não são ingênuos ou neutros e muitos menos os são os textos que ele "linkam"; então a sequência que podemos ler a partir desses links pode nos levar a construção de sentidos muito diferentes das pretendidas pelo autor.

E, hoje em dia, há alguns sites, que eu menciono no meu livro, em que você tem o texto, a palavra está com destaque, você percebe que é um link, mas ela não leva ao link semântico que ela prometia; ela é uma propaganda de um produto associado àquele texto, então ela abre um pop-up e caso você clique, ela lhe levará ao site onde ocorre a venda do produto.

Então, se um site, por exemplo, está falando de problemas de pele no verão e que todas as pessoas deveriam usar protetor solar, quando você percebe que as palavras "protetor solar" estão marcadas, você fica imaginando se aquele link irá levá-lo a mais informações relacionadas ao protetor solar, como saber o significado dos fatores, duração da proteção, etc., mas, na verdade, ele conduz a uma propaganda de um protetor solar. $\mathrm{O}$ mesmo ocorre quando esses links direcionam a textos que não estão no mesmo sentido de interpretação do texto original. Por exemplo, você está lendo uma notícia e, ao clicar em um link encontrado no decorrer do texto, acaba caindo em uma crônica ou poesia que trate daquele mesmo assunto ou que tenha alguma relação sugerida pelo autor do texto original. Primeiro, aquela relação pode não existir. Segundo, a mudança de esquema pode dificultar a interpretação; pode ser um elemento complicador da leitura. E, terceiro, a mudança de esquema de interpretação pode despertar o interesse do leitor para um nosso site ou texto, fazendo com que o leitor não retorne no texto original.

Esse assunto é muito complexo e o que nós imaginamos é o quão longe estamos 
de estudos teóricos e empíricos sobre os tipos de links e a funcionalidade deles hoje, nos sistemas hipertextuais, e de como nós, penso eu, paramos de pensar sobre os links e suas funções, que são, como nós já comentamos, os elementos centrais do hipertexto. Acho que conhecer a retórica dos links é tão importante hoje quanto conhecer a retórica dos operadores argumentativos; sem isso nós não conseguimos atribuir sentido ou, melhor dizendo, podemos atribuir sentidos que podem estar equivocados.

Eduardo Junqueira: É possível ensinar e escrever hipertextos na escola e para qual finalidade?

Luiz Fernando: É necessário! Mas, a finalidade, eu acho que não muda muito da finalidade de se ensinar a ler e a escrever. Tem que se ensinar a ler e a escrever para que o sujeito se constitua no texto, para que ele se identifique, para que ele compreenda a si mesmo e ao mundo que o cerca e para que ele perceba, entre em contato, vivencie outros mundos e realidades possíveis que vêm a nós por meio dos textos verbais, verbovisuais, sonoros, etc. Essa é a finalidade primordial do ensino da escrita e, claro, se o texto possibilita a construção da subjetividade, da alteridade, em última instância, também deverá promover um maior entendimento das diferenças entre as pessoas em todas as partes do mundo. Essa deve ser a função da escola: a educação para a paz, a educação para a convivência pacífica, mas só podemos ter paz e convivência se conhecermos de fato as outras pessoas, as outras culturas, enfim, conhecendo podemos nos reconhecer e nos reconhecendo podemos aceitar, talvez melhor, as diferenças todas.

Eduardo Junqueira: O que o professor que planeja elaborar um blog pode fazer para melhorar os hipertextos elaborados, a partir desse meio de comunicação e de aprendizagem?

Luiz Fernando: Falando em sistemas hipertextuais, os blogs são um exemplo claro, pois possibilitam o uso de alguns gadgets que nos inserem em determinados padrões hipertextuais. Certa vez, propus aos alunos que fizessem diagramas com todos os posts que havia em seus blogs da disciplina, de forma que os diagramas elaborados por eles, coloridos e bem acabados, revelassem a estrutura hipertextual do blog de cada um deles. Os quarenta blogs apresentaram mais ou menos o mesmo padrão, o padrão do hipertexto hierárquico, sendo que você tem categorias macros, que às vezes são as datas dos dias de aula ou da postagem ou as tags dos temas que o "blogueiro" costuma utilizar ou discutir e dentro daquelas tags macro, nós temos os comentários.

Agora, como melhorar os hipertextos elaborados, a partir desses instrumentos? $\mathrm{Eu}$ comentei anteriormente que nós temos poucos trabalhos discutindo práticas pedagógicas de ensino de uso do hipertexto. A proposta de analisar as estruturas dos blogs, que comentei acima, ajudou-as a perceber como o blog havia sido estruturado, não tanto por decisão deles, mas sim pela conformação entre os desejos e as possibilidades oferecidas pela ferramenta. Ou seja, os blogs permitem, no nosso caso, apenas acesso hierárquico aos textos, pois é um sistema hipertextual hierárquico e restritivo.

Com isso, admite-se que os blogs acabam permitindo pouco diálogo e pouca interação, até por que, nele, o ultimo post aparece primeiro. Por exemplo, se o professor criar uma discussão e der sete dias para os alunos postarem, se um aluno for postar no sexto dia ele provavelmente não irá ler todos os comentários, dará preferência aos últimos. Então, embora o blog permita algum tipo de organização hipertextual, normalmente o aluno acaba lendo o ultimo post, ou seja, só lê a novidade, então, como sistema hipertextual, eu acho que ele ficou viciado em uma forma de acesso. Não são muitos leitores que clicam nas tags para procurar temas específicos e mesmo que 
cliquem, se for um blog antigo e com bastante conteúdo, o leitor pode até abrir a tag e lerá as ultimas postagens, mas, só se ele estiver muito interessado em determinado tema é que vai rolar as páginas do blog até o final para ler todas as postagens.

Eduardo Junqueira: A produção de sentidos na escrita de um hipertexto é muito diferente da que ocorre na escrita tradicional?

Luiz Fernando: Olha, embora nós leiamos hipertextos e textos tradicionais, a nossa construção de sentido não é linear, nem em textos ou hipertextos. Então, no texto tradicional e no hipertexto, no sentido micro, ou seja, no sentido de linha, de frase, de sentença, é da esquerda para a direita, quando se trata de texto verbal. Agora, se nós lermos um texto tradicional de trinta linhas e um hipertexto de cinco linhas, a ideia da construção é a mesma, mas se pensarmos em um hipertexto que nos "linka" e na multimodalidade, aí podemos imaginar que esses inputs de linguagem, são trabalhados pelo cérebro em tempos e formas diferentes e até em hemisférios diferentes, portanto, a construção de sentido no nível neurológico é diferente.

A linguagem verbal tende a ser mais racional, enquanto a linguagem visual privilegia mais o canal emocional. A junção entre o emocional e o racional para a atribuição de sentido é um trabalho um pouco mais complicado, por ter uma sobrecarga de informação. Se texto ou imagem não forem bem entendidos ou interpretados, a construção de sentidos do conjunto multimodal pode ser prejudicada.

Por outro lado, sem formação escolar, mas não necessariamente, sobre como atribuir sentido, como ler imagens fixas ou em movimento, o leitor poderá não passar da leitura denotativa, perdendo outros sentidos mais profundos.

Sim, há uma diferença muito grande entre a construção de sentido em um hipertexto e um texto tradicional, imaginando também e resgatando aquela primeira questão, do que estamos chamando de texto, você imagine pegar os textos remixados. A atribuição de sentido neles é bem mais complexa, embora não pareça, do que a atribuição de um texto estritamente verbal. Então, a atribuição de sentido em um hipertexto, onde nós temos imagens como ilustração, é feita de uma forma, mas em um hipertexto, onde a imagem é central e o texto verbal seja um complemento, a construção de sentido é outra.

Volto a dizer, pensando dessa forma me parece, ainda, que nós temos poucas pesquisas com dados empíricos inclusive, sobre como funciona de fato a produção de sentidos em hipertextos. Nós vemos poucas publicações a respeito disso e quer me parecer, salvo um mau juízo, que nós estamos tão habituados já a clicar, a ler e a mexer com o hipertexto, nós os leitores, que damos esse trabalho como concluído e como desnecessário qualquer outra investigação ou aprofundamento. Pergunto-me se no caso do hipertexto não estaríamos ficando tão habituados a dizer que já sabemos ler ou navegar e a pensar que as crianças de hoje, nativas digitais, são mais inteligentes por saberem lidar com dispositivos e programas e, desta forma, não estaríamos negligenciando o ensino da leitura e da produção hipertextual.

Eduardo Junqueira: Em seu livro, você afirma que a web 2.0 está mais livre, mas ao mesmo tempo mais confusa. Isso não dificulta o seu uso na aprendizagem, particularmente com crianças e pré-adolescentes?

Luiz Fernando: É, a web 2.0 faz com que nos lembremos de um jargão do apresentador Chacrinha: "Não vim aqui para explicar, eu vim aqui para confundir", e é mais ou menos isso mesmo. Quando os sites nos tempos da web 1.0 eram feitos por especialistas, eles é que nomeavam as seções, os links estruturais dos sites e eles faziam essa nomeação com base nos estudos da própria ciência da informática. Quando nós, 
leigos, começamos a nomear as seções dos nossos sites, as tags dos blogs, acabamos nomeando categorias com nomes não padronizados, ou que, semanticamente, não fossem claros. Por exemplo: o que se pode esperar de uma tag com o nome de "Aula do dia 25 " é uma informação objetiva e que se encaixe dentro dessa categoria. Mas, ao clicar num sistema de busca com esses termos, surgirão milhões de resultados, pois quantas aulas não receberam a mesma tag? Como a quantidade de tags só tende a aumentar, a confusão na busca por informações relevantes também tende a aumentar. Estamos entrando num gargalo e acumulando muito lixo inaproveitável e que polui a busca.

Muitos sites aproveitam essa confusão para nos ludibriar. Por exemplo, se você entrar nos sites que oferecem download de programas e digitar o nome de um programa qualquer que você deseja baixar o link para download, é propositadamente semelhante ao link para download de programas antivírus, barras de navegação, aceleradores de download, etc. para que o usuário se confunda e baixe uma porção de coisas indesejáveis e difíceis de desinstalar. Não temos, como já disse, tantas pesquisas sobre o tamanho da confusão causada por desse logro, desse mau uso que confunde propositadamente o leitor. Porém, é necessário que a escola pense em formas de lidar com esses links maliciosos e educar também apara a proteção. O que temos, até agora, é aquele discurso marcado de que o aluno deve filtrar, saber qual informação é relevante ou não, mas pouca coisa além disso a gente tem avançado, então aí também há mais uma questão pendente.

Então, se você observar, vai verificar que o primeiro livro que eu escrevi (Hipertextos Multimodais: leitura e escrita na era digital - Paco Editorial, São Paulo, Jundiaí: 2010) com parte do conteúdo da tese, era um livro que eu achava ter resolvido algumas coisas, eu já tinha mais ou menos entendido um pouco sobre hipertexto e estava razoavelmente satisfeito e eu achei que cumpria meu papel acadêmico de divulgar meu trabalho de pesquisa. Mas logo de cara eu percebi que não era bem assim, que a função da ciência era mais do que isso, no meu caso especificamente, era fazer com que meus estudos chegassem à escola, e quando tentei pedagogizar os tipos de hipertexto e as funções retóricas dos links e âncoras, percebi as muitas lacunas acadêmicas ainda existentes e mais, as inúmeras dificuldades que sua introdução no cotidiano escolar revelava.

Eduardo Junqueira: A não linearidade do hipertexto pode ser vista como um fator positivo à aprendizagem e por quê?

Luiz Fernando: O que nós sabemos sobre a aprendizagem é que ela também não é linear e sabemos também que ela ocorre não em uma sequência do mais fácil para o mais difícil, já que essas categorias não são aplicadas igualmente para todos os conceitos e muito menos para todas as pessoas ou aprendizes, portanto, a não linearidade é parceira da aprendizagem, embora me pareça equivocada a ideia de que nós não pensamos de forma linear e essa não linearidade é que teria sugerido o surgimento do hipertexto. Primeiro porque aquele texto As you may think já afirma de um jeito que parece que nós pensamos de forma hipertextual e na verdade não dá certo, em uma instância, pode, sim, até não linearizar o pensamento, mas em outra instância não. Por exemplo, agora, para organizar meu pensamento aqui e transformar esse pensamento em resposta eu tenho que linearizar, que organizar; então em uma certa instância o pensamento é linear. Mas, também pensamos por imagens, também imaginamos um pensamento e essas imagens é que são depois traduzidas em linguagem verbal, há uma certa mística, talvez, nessa ideia de não linearidade.

Então quando você relaciona a não linearidade do hipertexto com a 
aprendizagem, o hipertexto também é linear no nível da sentença, no nível da oração como nós já conversamos, no nível de alguns períodos, então a ideia da não linearidade talvez já tenha sido explorada demais de forma um pouco inconsequente. A linearidade e a não linearidade no pensamento, no texto, no hipertexto existem em instâncias diferentes. Agora o problema é que nós construímos sentidos de forma não linear, nós raciocinamos ou racionalizamos o que vemos e o que sentimos, mas não na sequência em que vemos ou que sentimos. Essa reelaboração é todo um processo de construção da ideia e do pensamento que parte de fontes, de dados não lineares presentes na nossa memória ou que deram entrada em nossa memória em tempos distintos que depois nós reorganizamos para elaborar um pensamento.

Nesse sentido, não vejo nenhum problema do input de informações para nós na escola ou em qualquer outro lugar de forma não linear. Dependendo do pensamento que vamos elaborar, a entrada de uma ideia hoje só vai contribuir para alguma coisa em, digamos, um ano, trinta dias, sessenta dias e em outros casos talvez não, acabou de entrar e já me sugere a produção de alguma reflexão. Dessa forma, não vejo a linearidade ou a não linearidade como instâncias que se excluem mutuamente e muito menos que isso seja um problema para a construção de sentido tanto no hipertexto como no dia- a-dia.

Recebido em: outubro de 2013.

Aprovado em: março de 2014. 